\title{
Effect of fishing season on the fatty acid profile of Baltic herring
}

\author{
Janusz Pomianowski, Tomasz Żmijewski and Adam Wiżk \\ Department of Meat Technology and Chemistry, Faculty of Food Sciences, University of Warmia and Mazury in \\ Olsztyn, Olsztyn, Poland
}

\section{Abstract}

Marine fish are a good source of unsaturated fatty acids, high nutritional value protein, vitamins and minerals. Baltic herring is one of the most frequently caught fish in Poland ${ }^{(1)}$. It was demonstrated that the fishing season has an effect on the content of individual fatty acid fractions ${ }^{(2)}$.

The aim of the study was to analyse the fatty acid profile of Baltic herring flaps originating from two fishing seasons.

The study material were flaps of Baltic herring (Clupea harengus) originating from two fishing seasons (April-June following spawning and October-December prior to spawning). For each fishing season, six batches of raw material were examined $(\mathrm{n}=6)$. From each batch, flaps were taken from ten fish. The flaps were comminuted and thoroughly mixed to prepare an experimental sample from which adequate weights of analytical samples were taken. The quantitative and qualitative analysis of the fatty acid composition was conducted following the cold muscle lipid extraction with a mixture of chloroform : methanol (2:1). Fatty acid methylation was carried out with a chloroform : methanol : sulphuric acid mixture (100:100:1). The separation of fatty acids was performed by gas chromatography. A one-factor variance analysis method with Duncan's test $(\mathrm{P} \leq 0.05)$ was used to evaluate the variation of mean values.

The fishing season does not significantly affect the content of saturated and unsaturated fatty acids. Differences were found during the analysis of the individual groups of unsaturated acids. The amount of monounsaturated fatty acids in herring before spawning $(25.27 \%)$ was significantly lower than that after spawning $(35.91 \%)(\mathrm{P} \leq 0.05)$. The content of polyunsaturated fatty acids before spawning $(43.99 \%)$ was significantly higher than that after spawning $(33.49 \%)(\mathrm{P} \leq 0.05)$. Most changes in the fatty acid profile occur in the highly unsaturated fatty acids (HUFA). The most important change due to the health-promoting properties for humans is an increase in the amount of EPA from $6.24 \%$ to $9.84 \%$ after and before spawning, respectively. Analogous changes were demonstrated for DHA, whose amount increased from $9.64 \%$ to $24.56 \%$. The obtained results demonstrate a more favourable fatty acid profile in herring caught before spawning.

\section{Acknowledgements}

Project financially supported by Minister of Science and Higher Education in the range of the program entitled "Regional Initiative of Excellence" for the years 2019-2022, Project No. 010/RID/2018/19, amount of funding 12.000.000 PLN.

\section{Conflict of Interest}

There is no conflict of interest

\section{References}

1. Usydus Z. et al. (2011) Food Chem 126, 78-84.

2. Røjbek M., et al. (2014) ICES Journal of Marine Science 71(1), 56-71. 